\title{
Influência de extratos de formas evolutivas sobre atividades de oviposição de fêmeas de Aedes (s) albopictus (Skuse).
}

\author{
Influence of larval, pupal and eggs extracts on the oviposition behavior of \\ Aedes (s) albopictus (Skuse)
}

\section{Cristiano C.A. Marques*, Cristina Miranda*}

\begin{abstract}
MARQUES, C.C.A. \& MIRANDA, C. Influência de extratos de formas evolutivas sobre atividades de oviposição de fêmeas de Aedes (s) albopictus (Skuse). Rev. Saúde públ., S.Paulo, 26: $269-71,1992$. Extratos aquosos de larvas, pupas e ovos foram testados em relação à sua influência sobre o comportamento de oviposição de fêmeas de Aedes (s) albopictus a concentrações de: 1 larva/3 ml; 1 pupa/3ml; 1 ovo/3ml. Extratos de larvas e pupas tiveram um efeito atrativo sobre as fêmeas $(\alpha=0,05)$ e o extrato de ovos não exerceu influência sobre o comportamento de oviposição.
\end{abstract}

Descritores: Aedes, fisiologia. Oviposição. Comportamento animal, fisiologia.

\section{Introdução}

Aedes (s) albopictus, espécie recentemente introduzida no Brasil, encontra-se atualmente dispersa em vários Estados: Minas Gerais, Espírito Santo, Rio de Janeiro e São Paulo (PAHO $\left.{ }^{13}, 1987\right)$, onde está, em especial no Vale do Paraíba, amplamente distribuída. Essa espécie apresenta características importantes como a capacidade de colonizar o ambiente urbano, sendo o ambiente silvestre, aparentemente, seu habitat natural. Devido a esta característica, as medidas de controle e vigilância preconizadas eventualmente não surtem efeito (Marques e col. ${ }^{10}, 1988$ ). Estudos conduzidos com linhagens de Aedes (s) albopictus, provenientes da América do Norte e América do Sul, tiveram seus resultados confirmados em relação à competência vetorial para 18 arboviroses. No entanto, o maior perigo apresentado pelo Aedes $(s)$ albopictus no Hemisfério Ocidental, é seu potencial em ser vetor de viroses como dengue $1,2,3,4$, febre amarela e La Crosse (Mitchell ${ }^{12}$, 1991).

A atividade ovipositora de fềmeas do gênero Aedes sp já é bem conhecida e descrita pela literatura, podendo estar associada à presença de formas imaturas nas águas do criadouro (Soman e Reuben ${ }^{16}$, 1970; Gubler ${ }^{7}$, 1971; Trimble e Wellington ${ }^{17}$, 1980; Maire ${ }^{9}$,

* Superintendência de Controle de Endemias - Taubaté, SP - Brasil.

Separatas/Reprints: C.C.A. Marques - Av. 9 de Julho, 37212100 - Taubaté, SP - Brasil.

Publicação financiada pela FAPESP. Processo Saúde Coletiva 91/4994-0.
1984; Consoli $\left.{ }^{5}, 1988\right)$ à presença de matétia orgânica decomposta (Gerhardt ${ }^{6}$, 1959; Bond e Fay ${ }^{4}, 1969$; Ahmadi e McClelland ${ }^{1}$, 1983) e, até mesmo, à presença de séries homólogas de ésteres de àcidos graxos (Perry e Fay, ${ }^{14}$ 1967). Alguns pesquisadores indicam uma relação entre bactérias ou metabólitos bacterianos presentes no criadouro, com a escolha destes pelas espécies estudadas (Hazard e col. ${ }^{8}, 1967$; Robert e Hsi ${ }^{15}$, 1977).

O presente trabalho consiste em avaliar a ação de extratos de larvas, pupas e ovos sobre a atividade ovipositora de fêmeas de Aedes (s) albopictus, objetivando e utilização destes extratos em armadilhas de ovos (OVITRAP) ou armadilhas autocídas. Ou seja, tem-se como perspectiva o desenvolvimento de um instrumento competitivo para o controle e vigilância entomológica desta espécie.

\section{Material e Método}

Os mosquitos foram obtidos da colônia mantida desde 1987, na Superintendência de Controle de Endemias - Serviço Regional-3 Taubaté - Estado de São Paulo. As características desta colonia foram descritas em Marques e col. ${ }^{11}, 1989$.

Fóram usados, aproximadamente, $200 \mathrm{ma}$ chos e 200 fêmeas, alimentadas segundo técnica já descrita em Marques e col. ${ }^{2}$; 4 dias após o primeiro repasto sangüíneo, utilizandose cobaias, foram of erecidos dois recipientes de vidro âmbar $(8 \mathrm{~cm}$ de diâmentro; $100 \mathrm{ml})$, 
referentes ao controle e ao teste, durante 24 horas. O recipiente-controle conteve $50 \mathrm{ml}$ de água destilada e no recipiente-teste foram colocados $50 \mathrm{ml}$ de extrato a ser testado, ambos devidamente revestidos com papel de filtro como substrato. $O$ número de ovos colocados em cada recipiente foi, então, contado.

Para cada extrato testado foram feitas 8 repetições, modificando-se a posição dos recipientes na gaiola, (em diagonal).

- Extratos larvários: 50 larvas de quarto estádio foram lavadas três vezes em água destilada. Em seguida, foram trituradas e adicionados $150 \mathrm{ml}$ de água destilada, após o que filtrou-se através de papel de filtro.

- Extratos pupais: 50 pupas de um dia foram lavadas três vezes em água destilada. Seguiuse procedimento análogo adotado para as larvas.

- Extratos de ovos: 150 ovos foram macerados em $150 \mathrm{ml}$ de água destilada e filtrados através de papel de filtro.

\section{Resultados}

O número de ovos obtidos pode ser observado na Tabela, com destaque para:

- Extratos larvários: Nos recipientes contendo os extratos larvários foram colocados $\mathbf{5 8 7 , 1 3}$ $\pm 350,47$ ovos contra $159,75 \pm 96,26$ ovos nos recipientes controle.

A comparação entre as médias demonstrou serem estas significativamente diferentes.

O número total de ovos contados nesse recipiente $f(i$ de 5.975 .

- Extratos pupais: Nos recipientes contendo os extratos pupais foram colocados em média $318,00 \pm 216$ ovos e $90,00 \pm 46,55$ ovos nos recipientes controle. As médias foram estatisticamente diferentes e o total de ovos neste experimento foi 2.226 .
- Extratos de ovos: As médias dos ovos colocados não foram estatisticamente diferentes: $63,13 \pm 43,70$ ovos nos recipientes contendo os extratos de ovos e $57,13 \pm 33,25$ ovos no recipiente-controle. O número total de ovos contados nestes experimento foi 962 .

\section{Discussão}

Os resultados obtidos no presente trabatho indicam que a atividade de oviposição das fêmeas de Aedes albopictus sofreu influência de extratos de larvas e pupas na concentração de uma larva (pupa) $/ 3 \mathrm{ml}$, fato este não observado por Gubler ${ }^{7}$ (1971), para Aedes albopictus conforme afirmativa: "A presença de lar-. vas e pupas nas águas dos criadouros não exerceu efeito atrativo sobre a atividade de oviposição das fêmeas. Entretanto, alguma substância atraente de oviposição foi liberada nas águas dos criadouros por fêmeas de Aedes albopictus, pois mesmos as fêmeas de Aedes polynesiensis preferiam águas contaminadas pela presença anterior de ovos de Aedes albopictus".

Andreadis $^{2}$ (1977), observou que as fêmeas de Culex salinarius fazem sua oviposição preferencialmente em águas nas quais pupas se desenvolveram. Fenômeno semelhante já tinha sido observado por Soman e Reuben ${ }^{16}$ (1970), quando fêmeas de Aedes aegypti mostraram preferência por água contendo estágios imaturos de suas próprias espécies.

Ecologicamente, este é um fenômeno adaptativo importante pois a presença de formas imaturas vivas parece exercer um estímulo para que ocorra o oviposição neste criadouro, ou seja, este seria um criadouro viável para a reprodução desta espécie.

Bentley e Day ${ }^{3}$ (1989), colocam que muitos experimentos relatados sobre o comportamento de oviposição, em laboratório, não refletem, necessariamente, o comportamento do mosquito em campo. Estes autores vão mais além, afirmando que muitos destes comportamentos relatados podem ser artefatos de laboratório, podendo não ser relevantes para o

Tabela. Número de ovos obtidos em 8 testes, por tipo de extrato (teste e controle).

\begin{tabular}{|c|c|c|c|c|}
\hline Extrato & $\begin{array}{c}\text { Teste } \\
\overline{\bar{X}} \pm \mathrm{SD}\end{array}$ & $\begin{array}{l}\text { Controle } \\
\bar{X} \pm S D\end{array}$ & $\begin{array}{c}\text { Student's } \\
\text { (t) }\end{array}$ & $\begin{array}{c}\text { Probabilidade } \\
\text { (P) }\end{array}$ \\
\hline Larvas & $587,13 \pm 350,17$ & $159,75 \pm 96,26$ & 3,33 & $P<0,05$ \\
\hline Pupas & $318,00 \pm 216,54$ & $90,00 \pm 46,55$ & 2,72 & $P<0,05$ \\
\hline Ovos & $63,13 \pm 43,70$ & $57,13 \pm 33,25$ & 0,31 & $P>0,05$ \\
\hline
\end{tabular}


comportamento na natureza. Torna-se, então, necessário ressaltar a importância de futuros estudos para avaliar estes extratos em campo, assim como, elucidar as substâncias ativas que atuam sobre o comportamento de oviposição e que estão presentes nos estágios imaturos testados. Vale ressaltar que testes preliminares utilizando água que conteve larvas do quarto estádio não apresentam efeito atrativo significante $(\alpha=0,05)$ para oviposição.

MARQUES, C.C.A. \& MIRANDA, C. [Influence of larval, pupal and eggs extracts on the oviposition behavior of Aedes (s) albopictus

(Skuse)]. Rev. Saúde públ., S. Paulo, 26: 269-71, 1992. Larval, pupae and egg water extracts were tested for their influence on the oviposition behavior of Aedes (s) albopictus females. Significant $(\alpha=0.05)$ attraction was exercised by larval and pupal extracts containing 1 larva $3 \mathrm{ml}$ and $1 \mathrm{pupa} / 3 \mathrm{ml}$. Eggs water extract containing 1 $\mathrm{egg} / 3 \mathrm{ml}$ did not influence the oviposition.

Keywords: Aedes, physiology. Oviposition. Behavior, animal, physiology.

\section{Referências Bibliográficas}

1. AHMADI, A. \& McCLELLAND, A.H. Oviposition attractants of the western treehole mosquito, Aedes sierrensis. Mosquito News, 43: 343-5,1983.

2. ANDREADIS, T.G. An oviposition attractant of pupal origin in Culex salinarius. Mosquito News, 37: 53-7, 1977.

3. BENTHEY, M.D. \& DAY, J.F. Chemical ecology and behavioral aspects of mosquito oviposition. Ann. Rev. Ent., 34: 401-21, 1989.

4. BOND, H.A. \& FAY, R.W. Factors influencing Aedes aegypti occurrence in containers. Mosquito News, 29: 113-6, 1969.

5. CONSOLI, R.A.G.B. \& TEDXEIRA, M.A. Influence of larval and pupal products on the oviposition behaviour of Aedes fluviatilis (LUTZ) (Diptera: Culicidae), Mem. Inst. Oswaldo Cruz, 83: 213-8, 1988.

6. GERHARDT, R.M. The influence of soil fermentation on oviposition site selection by mosquitos. Mosquito News, 19: 151-5, 1959.
7. GUBLER, D.J. Studies on the comparative oviposition behaviour of Aedes (stegomyia) albopictus and Aedes (stegomyia) polynesiensis. Marks. J. med. Ent., 8: 675-82, 1971.

8. HAZARD, E.I.; MAYER, M.S.; SAVAGE, K.E. Atraction and oviposition stimulation of gravid female mosquitoes by Bacteria isolated from hay infusions. Mosquito News, 27: 133-6, 1967.

9. MAIRE, A. An analysis of the ovipositional response of Aedes atropalpus to experimental oviposition waters. Mosquito News, 44: 325-9, 1984.

10. MARQUES, G.R.A.M.; MARQUES, C.C.A.; KHURIYEH, A.C.C.L; SOBRAL, I.M. Aspectos do controle de vetores da dengue e febre amarela no período de junho de 1985 a abril de 1988, na região do Vale do Paraíba e Litoral Norte do Estado de São Paulo - Brasil. In: Proceedings of the International Symposium of Yellow Fever and Dengue, Rio de Janeiro, 1988. p. 168.

11. MARQUES, G.R.A.M.; MARQUES, C.C.A.; SOBRAL, I.M.; BRITO, M. Desenvolvimento e manutenção de uma colônia de Aedes (stegomyia) albopictus (Skuse) (Diptera: Culicidae). In: Congresso Brasileiro de Entomologia, 12\%, Belo Horizonte, M.G., 1989. Anais. Belo Horizonte, 1989. p. 468.

12. MITCHELL, C.J. Vector competence of North and South American strains of Aedes albopictus for certain arboviruses: a review. J. Amer. Mosquito Control Ass., 7: 446-51, 1991.

13. PAN AMERICAN HEALTH ORGANIZATION Aedes albopictus in the Americas. Washington, D.C., 1987. (CE 99/15:1-56).

14. PERRY, A.S. \& FAY, R.W. Correlation of chemical constitution and physical properties of fatty acid esters with oviposition response of Aedes aegypti. Mosquito News, 27: 175-82, 1967.

15. ROBERTS, D.R. \& HSI, B.P. A method of evaluating ovipositional attractants of Aedes aegypti (Diptera: Culicidae) with preliminary results. J. med. Ent., 14: $129-31,1977$.

16. SOMAN, R.S. \& REUBEN, R. Studies on the preference shownby ovipositing females of Aedes aegypti for water containing immature stages of the same species. J. med. Ent., 7: 485-9, 1970.

17. TRIMBLE, R.M. \& WELLINGTON, W.G. Oviposition stimulant associated with fourth instar larvae of Aedes togoi (Diptera: Culicidae). J. med. Ent., 17: 509-14, 1980.

Recebido para publicaçāo em 14/1/1992 Reapresentado em 15/4/1942 Aprovado para publicaçāo em 13/5/1992 